UDC 699.812.3

Author: AHMED Abdulbaset Arabi A, postgraduate student of the Department «Information Security» Belarusian State University of Informatics and Radioelectronics, Minsk, Belarus; V.Horujey st., 10-151, Minsk, Belarus, 220123; bast.ahmed.67@mail.ru;

Author: NASONOVA Natalia Viktorovna, Ph.D. in Engineering, Associate Professor of the Department «Information Security» Belarussian State University of Informatics and Radioelectronics, Minsk, Belarus; 2nd Poselkovaya, 24-1, Minsk, Belarus, 220113; nasonovan@bsuir.by;

Author: PULKO Tatyana Aleksandrovna, Ph.D. in Engineering, Associate Professor of the Department «Information Security» Belarussian State University of Informatics and Radioelectronics, Minsk, Belarus; Orlovskay st., 29-33, Minsk, Belarus, 220068; naig@tut.by;

Author: LYNKOV Leonid Mikhailovich, Doctor of Engineering, Professor, Head of the Department «Information Security» Belarussian State University of Informatics and Radioelectronics, Minsk, Belarus; Independence Avenue, 157-197, Minsk, Belarus, 220114; leonid@bsuir.by

\title{
FINISHING PANELS FOR ELECTROMAGNETIC SHIELDED PREMISES ON THE BASIS OF NANOSTRUCTURED COMPOSITE MATERIALS
}

\section{ExTENDED AbSTRACT:}

A wide utilization of electronic equipment produces the necessity to integrate building and shielding technologies. This would make it possible to construct premises and buildings, capable of attenuation of the electromagnetic fields, generated by industrial and household sources. Such kinds of premises would solve the problems of electromagnetic compatibility, uncontrolled effect of electromagnetic radiation (EMR) on human organism, protection of critical types of information assets, processed by automatic facilities. In addition to the high shielding effectiveness the materials should ensure the fire safety in the premises. The developed multilayered shielding materials based on composites, which are characterized by high dielectric and magnetic losses, ensure the EMR attenuation $20 \ldots 35 \mathrm{~dB}$ in the frequency range of $0,7 \ldots 17 \mathrm{GHz}$. The EMR reflection factor, ensured by the suggested materials, is $-5 . .-1 \mathrm{~dB}$. Open fire $\left(+1700^{\circ} \mathrm{C}\right)$ impact on the developed materials was studied and the burning-through time for different samples was determined. The burning-through time is sufficiently increased up to $140 \mathrm{~s}$ due to hygroscopic aqueous solutions application in the composite materials content.

Key words: fire safety, composite materials, shielding effectiveness. 
MACHINE-REAdAbLE INFORMATION ON CC-LiCENSES (HTML-CODE) IN METADATA OF THE PAPER

$<$ a rel=»license» href=»http://creativecommons.org/licenses/by/4.0/»><img alt=» Лицензия Creative Commons» style=»border-width:0» src=»https://i.creativecommons.org/l/by/4.0/88x31.png» $/></ \mathrm{a}><$ br $/>$ Произведение "<span xmlns:dct=»http://purl.org/dc/terms/» href=»http://purl.org/dc/dcmitype/Text» property=»dct:title» rel=»dct:type» $>$ Finishing panels for electromagnetic shielded premises on the basis of nanostructured composite material $</$ span $>$ » созданное автором по имени <a xmlns:cc=» http://creativecommons.org/ns\#» href=» Nanotehnologii v stroitel'stve = Nanotechnologies in Construction. 2015, Vol. 7, no. 5, pp. 87-101. DOI: dx.doi.org/10.15828/2075-8545-2015-7-5-87101» property=»cc:attributionName» rel=»cc:attributionURL»>Ahmed A.A., Nasonova N.V., Pulko T.A., Lynkou L.M. $</$ a >, публикуется на условиях < a rel=»license» href=»http://creativecommons.org/licenses/by/4.0/»>лицензии Creative Commons «Attribution» («Атрибуция») 4.0 Всемирная</a $>$. $<\mathrm{br} />$ Основано на произведении с $<\mathrm{a}$ xmlns:dct=»http://purl. org/dc/terms/» href=» http://nanobuild.ru/en_EN/nanobuild-5-2015/»rel=»dct:source» > http://nanobuild.ru/en_EN/ nanobuild-5-2015/</a $>$. $<\mathrm{br} />$ Разрешения, выходящие за рамки данной лицензии, могут быть доступны на странице $<$ a xmlns:cc=»http://creativecommons.org/ns\#»href=»naig@tut.by»rel=»cc:morePermissions»>naig@tut.by</a>.

\section{References:}

1. Kechiev L.N., Stepanov P.V. Electromagnetic compatibility and information security in telecommunication systems [JeMS i informacionnaja bezopasnost' v sistemah telekommunikacij]. Moscow, Publishing House «Tehnologii», 2005, $320 \mathrm{~s}$.

2. Akbashev B.B., Kuprienko V.M. The design concept to protect objects from external electromagnetic influence [Koncepcija proektirovanija zashhity ob'ektov ot vneshnih jelektromagnitnyh vozdejstvij]. Tehnologii jelektromagnitnoj sovmestimosti [Technologies of electromagnetic compatibility]. 2009, № 1, pp. 58-63.

3. Akbashev B.B. Shielded rooms [Jekranirovannye pomeshhenija]. Moscow, Publishing House MIJeM, 2008, 175 p.

4. Uill'jams T., Armstrong $K$. Electromagnetic compatibility for systems and equipment [JeMS dlja sistem i ustanovok]. Moscow, Publishing House «Tehnologii», 2004,508 p.

5. Hemming L.H. Architectural Electromagnetic Shielding Handbook. A Design and Specification Guide. - IEEE Press, 1992. - 222 p.

6. Belousova E.S., Mahmood M.Sh., Lynkov L.M., Nasonova N.V. Radio shielding properties of concrete based on shungite nanomaterials Nanotehnologii v stroitel'stve $=$ Nanotechnologies in Construction. 2013, Vol. 5, no. 2. pp. 56-67. Available at: http://nanobuild.ru/ru_RU (Data of access: 12.04.2015).

7. Mahmood M.Sh., Pulko T.A., Prudnik A.M., Lynkov L.M. [Uglerodsoderzhashhie otdelochnye materialy dlja zashhity pomeshhenij special'nogo naznachenija]. Security of information technologies [Bezopasnost' informacionnyh tehnologij]. 2012, № 1, pp. 192-194.

8. Mahmood M.Sh., Belousova E.S., Prudnik A.M., Lyn'kov L.M. The influence of bischofite additives on the properties of pyramide shields of electromagnetic radiation for information protection and ecology safety [Vlijanie dobavok bishofi- 
ta na harakteristiki piramidoobraznyh jekranov jelektromagnitnogo izluchenija dlja sredstv zashhity informacii i jekologicheskoj bezopasnosti]. Proc. of BGUIR. 2014, № 1 (79), pp. 89-92.

9. Kazanceva H.E., Ryvkina N.G., Chmutin I.A. Prospective materials for absorbers of electomagnetic waves of superhigh-frequency range [Perspektivnye materialy dlja poglotitelej jelektromagnitnyh voln sverhvysokochastotnogo diapazona]. [Radiotehnika i jelektronika]. 2003, V. 48, № 2, pp.196-209.

10. Silva E., Rocha E.J., Lins P., Nóbrega S. Characterization of electromagnetic radiation absorber materials. IEEE MTT-S International Conference on Microwave and Optoelectronics. 2005, pp. $326-329$.

11. Mahmood, M.Sh., Nasonova N.V., Krishtopova E.A., Borbotko T.V., Prudnik A.M., Lynkov L.M. Schungite-containing composite shields of electromagnetic radiation [Shungitsoderzhashhie kompozicionnye jekrany jelektromagnitnogo izluchenija]. Minsk: Bestprint, 2013, 195 p.

12. Grishhenkova V.A., Vladimirov D.N., Fukina V.A., Handogina E.N., Shapovalova E.I. A protection fabric against electromagnetic radiation [Tkan dlja zashhity ot jelektromagnitnyh izluchenij]. Patent RF 2411315. 2011.

13. Belousova E.S, Nasonova N.V., Lynkov L.M. et al. Fire-resistant shielding coating based on shungite-containing paint. Nanotehnologii v stroitel'stve $=$ Nanotechnologies in Construction. 2013, Vol. 5, no. 4. pp. 97-109. Available at: http:// nanobuild.ru/magazine/nb/Nanobuild_4_2013.pdf (Date of Access 05.05.2015).

14. GOST 30402-96. Construction materials. Flammability test method [Materialy stroitel'nye. Metod ispytanija na vosplamenjaemost']. Moscow, Minstroj Rossii, $1996,33 \mathrm{p}$.

\section{DEAR COLleAgues!}

THE REFERENCE TO THIS PAPER HAS THE FOLLOWING CITATION FORMAT:

Ahmed A.A., Nasonova N.V., Pulko T.A., Lynkou L.M. Finishing panels for electromagnetic shielded premises on the basis of nanostructured composite material. Nanotehnologii v stroitel'stve $=$ Nanotechnologies in Construction. 2015, Vol. 7, no. 5, pp. 87-101. DOI: dx.doi.org/10.15828/2075-8545-2015-7-5-87-101. (In Russian). 
Автор: АХМЕД Абдулбасет Араби А., аспирант каф. «Защита информации» Белорусского государственного университета информатики и радиоэлектроники, г. Минск, Беларусь; ул. В. Хоружей, 10-151, г. Минск, Республика Беларусь, 220123; bast.ahmed.67@mail.ru; Автор: НАСОНОВА Наталья Викторовна, канд. техн. наук, доцент каф. «Защита информации» Белорусского государственного университета информатики и радиоэлектроники, г. Минск, Беларусь; ул. 2-ая Поселковая, 24-1, г. Минск, Республика Беларусь, 220113; nasonovan@bsuir.by;

Автор: ПУлКО Татьяна Александровна, канд. техн. наук, доцент каф. «Защита информации» Белорусского государственного университета информатики и радиоэлектроники, г. Минск, Беларусь; ул. Орловская, 29-33, г. Минск, Республика Беларусь, 220068; naig@tut.by;

Автор: ЛЫНЬКОВ Леонид Михайлович, д-р технических наук, проф., зав. каф. «Защита информации» Белорусского государственного университета информатики и радиоэлектроники, г. Минск, Беларусь; пр. Независимости, д. 157, кв. 197, г. Минск, Республика Беларусь, 220114; leonid@bsuir.by

\section{ОТДЕЛОЧНЫЕ ПАНЕЛИ ДЛЯ СОЗДАНИЯ ЭКРАНИРОВАННЫХ ПОМЕЩЕНИЙ НА ОСНОВЕ НАНОСТРУКТУРИРОВАННЫХ КОМПОЗИЦИОННЫХ МАТЕРИАЛОВ}

\section{АННОТАЦИЯ К СТАТЬЕ (АВТОРСКОе РЕЗЮMе, РЕФЕРАТ):}

Развитие электронных устройств и их повсеместное распространение приводит к необходимости интеграции строительных и экранирующих технологий, что позволило бы создавать строительные материалы для зданий и выделенных помещений, снижающих уровень распространяющихся электромагнитных полей бытовых и промышленных источников. Такие помещения могут использоваться для решения проблем электромагнитной совместимости, неконтролируемого воздействия электромагнитных излучений (ЭМИ) на организм человека, обеспечения защиты критичной информации, обрабатываемой автоматическими средствами. Помимо высокой эффективности экранирования, материалы для строительства или отделки помещений должны удовлетворять определенным требованиям по пожарной безопасности. Проведенные исследования многослойных экранирующих материалов на основе композитов с магнитными и диэлектрическими потерями показали, что эффективность экранирования ЭМИ составляет $20 . . .35$ дБ в диапазоне частот 0,7...17 ГГц. Коэффициент отражения ЭМИ исследованными материалами составляет $-5 . . .-1$ дБ. При исследованиях воздействия открытого пламени $\left(+1700^{\circ} \mathrm{C}\right)$ определялось время сквозного прогорания образцов. Показано, что использование в составе композиционных 
материалов гигроскопичных водных растворов позволяет увеличить время сквозного прогорания материала толщиной 0,3 мм до 140 c.

Ключевые слова: пожарная безопасность, композиционные материалы, эффективность экранирования.

DOI: dx.doi.org/10.15828/2075-8545-2015-7-5-87-101

МАШИНОЧИТАЕМАЯ ИНФОРМАЦИЯ о СС-ЛИЦЕНЗИИ В МЕТАДАННЫХ СТАТЬИ (HTML-КОД):

$<$ a rel=»license» href=»http://creativecommons.org/licenses/by/4.0/»><img alt=»Лицензия Creative Commons» style=»border-width:0» src=»https://i.creativecommons.org/l/by/4.0/88x31.png» $/></$ a $><$ br $/>$ Произведение «<span xmlns:dct=»http://purl.org/dc/terms/»href=»http://purl.org/dc/dcmitype/Text»property=»dct:title» $\mathrm{rel}=» d c t: t y p e »>0$ тделочные панели для создания экранированных помещений на основе наноструктурированных ком- позиционных материалов</span>» созданное автором по имени <a xmlns:cc=»http://creativecommons.org/ ns\# 》 href=»Нанотехнологии в строительстве. - 2015. - Том 7, № 5. - C. 87-101. - DOI: dx.doi.org/10.15828/20758545-2015-7-5-87-101» property=»cc:attributionName» rel=»cc:attributionURL»>Aхмед А.А., Насонова Н.В., Пулко Т.А., Лыньков Л.М.</a>, публикуется на условиях <a rel=»license» href=»http://creativecommons.org/licenses/ by/4.0/»>лицензии Creative Commons "Attribution» («Атрибуция») 4.0 Всемирная $</ \mathrm{a}>$. $<$ br $/>$ Основано на произведении с <a xmlns:dct=»http://purl.org/dc/terms/» href=»http://nanobuild.ru/ru RU/nanobuild-5-2015/» rel=»dct:source»>http:// nanobuild.ru/ru_RU/nanobuild-5-2015/</a>. $<$ br /> Разрешения, выходящие за рамки данной лицензии, могут быть доступны на странице <a xmlns:cc=»http://creativecommons.org/ns\#»href=»naig@tut.by» rel=»cc:morePermissions»>naig@ tut. by $</ a>$.

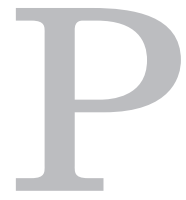

азвитие электронных устройств и расширение областей их применения - в медицине, финансах, производстве - и увеличение скоростей обработки информации приводит к усилению необходимости учитывать влияние их побочных электромагнитных излучений на окружающее оборудование и работающий персонал. Кроме того, часто электронное оборудование должно быть электромагнитно изолировано от среды, в которой оно находится, для обеспечения его устойчивой и бесперебойной работы в независимости от внешних возмущающих электрических переходных процессов (молний, мощных переключателей, интенсивных радиочастотных полей, мощных магнитных полей). Отдельный класс требований по ограничению побочных электромагнитных излучений средств обработки информации устанавливается для средств технической защиты информации от утечки по электромагнитным каналам. При использовании вычислительной техники для обработки высококритичной информации с высокой степенью конфиденциальности, целостности требуется эффективная защита такого обо- 
рудования от влияния как непреднамеренных, так и преднамеренных электромагнитных воздействий $[1,2]$.

Описанные выше проблемы подводят к новому решению - созданию интегрированных экранированных помещений, в которых материалы и конструкции одновременно отвечают требованиям эфрективного экранирования для электрических, магнитных или электромагнитных полей и строительства в зависимости от поставленной задачи $[3,4,5,6]$. В зависимости от назначения существующие помещения могут отделываться специальными экранирующими материалами для обеспечения электромагнитной совместимости устройств, препятствования проникновения извне и наружу электромагнитных волн и снижения электромагнитной нагрузки на работающий персонал [7,8].

Создание экранирующих и радиопоглощающих ЭМИ материалов включает как применение материалов, обладающих резистивными, магнитными и диэлектрическими потерями, так и применение конструктивных приемов для подавления энергии падающего и отраженного электромагнитного излучения [9,10].

Многослойные конструкции позволяют увеличить эффективность экранирования ЭМИ и снизить коэффициент отражения ЭМИ от конструкции за счет создания условий для согласования волновых сопротивлений свободного пространства и материала, а также для компенсации энергии электромагнитных волн, отраженных от границ раздела между слоями [11].

Металлы и изделия на их основе (листы, сетки, фольга, краска и пр.) обладают высокой эффективностью экранирования ЭМИ за счет отражения 99,9\% доли энергии падающего электромагнитного излучения вследствие высокой проводимости этого типа материалов.

Ферритовые материалы используются для снижения коэффициента отражения металлических поверхностей в относительно нешироком диапазоне частот. Исследовались образцы экранирующих материалов в виде ПЭФ тканых полотен толщиной 0,3 мм с вплетенным ферромагнитным микропроводом. Ткань включает нити, выполненные из наноструктурного ферромагнитного микропровода в стеклянной изоляции, которые скручены при 100-800 кр/м с основными и уточными нитями из натуральных и/или химических волокон и составляют 1,0-3,2\% от поверхностной плотности ткани [12]. Аморфный наноструктурный ферромагнитный микропровод в стеклянной изоляции состоит из фер- 
ромагнитного сплава $\mathrm{Fe}, \mathrm{Co}, \mathrm{Ni}$ и металлоида $\mathrm{B}, \mathrm{Si}, \mathrm{C} . \mathrm{B}$ низкочастотном диапазоне 30-100 МГц ослабление ЭМИ такой тканью составляет 20-40 дБ. Соотношение нитей утка к нитям с ферромагнитным микропроводом $-1: 2$.

Композиционные нетканые материалы с наполнением углеродными волокнами также могут применяться для создания радиопоглотителей ЭМИ. Принцип действия таких материалов основан на резистивных потерях в материале при прохождении по нему электромагнитной волны.

Высокие диэлектрические потери воды в СВЧ-диапазоне обусловливают применение ее и растворов на ее основе для создания широкополосных экранов и поглотителей ЭМИ диапазона СВЧ. Стабилизации концентрации воды в составе материала можно достичь, применяя гигроскопичные соли в качестве компонентов раствора. Пропитка водой и водными растворами волокнистых матриц с большой удельной поверхностью обусловливает присутствие значительной доли наноструктурированной воды в приграничных с поверхностью твердого тела слоях, что, в свою очередь, отражается на электрофизических и электромагнитных характеристиках таких водосодержащих композиционных материалов. Комбинирование материалов с различными типами потерь для электромагнитного излучения позволяет повысить эффективность экранирования, уменьшить коэффициент отражения ЭМИ и расширить частотный диапазон получаемых экранирующих и радиопоглощающих изделий.

Исследовались экранирующие характеристики многослойных экранирующих конструкций, состоящие из слоев диэлектрических и магнитных материалов на металлической подложке. Состав исследованных образцов приведен в табл.

Фотографии внешнего вида образцов многослойных экранирующих конструкций представлены на рис. 1.

Измерения экранирующих характеристик (ослабление, коэффициент отражения ЭМИ) проводились в двух частотных диапазонах: 0,7 ... 3,0 и $2 . .17$ ГГц на автоматизированном измерителе модуля коэффициентов передачи и отражения SNA 0.01-18 оценкой коэффициентов передачи и отражения волноводного тракта с рупорными антеннами $6 \Pi-23 \mathrm{M}$, в раскрыве рупора антенны, в диапазоне частот $2 \ldots 17$ ГГц (рис. 2). Ослабление, вносимое исследуемым образцом, определяется отношением напряженностей волн, падающей и прошедшей через образец, выделя- 
Таблица

Описание образцов многослойных экранирующих материалов

\begin{tabular}{|c|c|c|}
\hline $\begin{array}{c}\text { Обозначе- } \\
\text { ние об- } \\
\text { разца }\end{array}$ & Состав слоев & $\begin{array}{l}\text { Состав про- } \\
\text { питывающе- } \\
\text { го раствора }\end{array}$ \\
\hline 1082 & $\begin{array}{l}\text { Маскировочная ПЭФ сетка / ПЭФ полотно с вплетен- } \\
\text { ным ферромагнитным микропроводом / диэлектриче- } \\
\text { ская ПЭТ прослойка металлическая фольга }\end{array}$ & $\begin{array}{l}\text { Водный } \\
\text { раствор } \\
\mathrm{CaCl}_{2}\end{array}$ \\
\hline 1083 & $\begin{array}{l}\text { Маскировочная ПЭФ сетка / ПЭФ полотно с вплетен- } \\
\text { ным ферромагнитным микропроводом / диэлектриче- } \\
\text { ская ПЭТ прослойка металлическая фольга }\end{array}$ & - \\
\hline 1084 & $\begin{array}{l}\text { Маскировочная ПЭФ сетка / ПЭФ полотно с вплетен- } \\
\text { ным ферромагнитным микропроводом / диэлектриче- } \\
\text { ская ПЭТ прослойка металлическая фольга }\end{array}$ & Вода \\
\hline 1086 & $\begin{array}{l}\text { Маскировочная ПЭФ полотно с вплетенным ферромаг- } \\
\text { нитным микропроводом / синтетический волокнистый } \\
\text { нетканый материал с углеродным наполнением/ гипсо- } \\
\text { картон толщиной } 10 \text { мм }\end{array}$ & - \\
\hline 1090 & $\begin{array}{l}\text { ПЭФ полотно с вплетенным ферромагнитным микро- } \\
\text { проводом / гипсокартон толщиной } 10 \text { мм }\end{array}$ & - \\
\hline 1091-1 & $\begin{array}{l}\text { ПЭФ полотно с вплетенным ферромагнитным микро- } \\
\text { проводом / гипсокартон толщиной } 10 \text { мм }\end{array}$ & $\begin{array}{l}\text { Водный } \\
\text { раствор } \\
\mathrm{CaCl}_{2}\end{array}$ \\
\hline
\end{tabular}

емых блоками А и В. Коэффициент отражения $\mathrm{R}$ характеризует долю падающей энергии ЭМИ, отраженную от образца. Напряженности поля волн измеряются блоками А и В, затем блок обработки сигналов производит вычисление отношений. Коэффициент отражения ЭМИ измерялся в режимах согласованной нагрузки и тракта, нагруженного на металлическую отражающую пластину (КЗ):

$$
\begin{aligned}
& A=20 \log \left(\sqrt{\frac{E_{\text {nad }}}{E_{\text {nрou }}}}\right), \partial Б \\
& R=20 \log \left(\sqrt{\frac{E_{\text {omp }}}{E_{\text {nad }}}}\right), \partial Б,
\end{aligned}
$$


где $E_{\text {отр }}, E_{\text {пад }}$ - напряженность поля, выделенного детектором отраженной и падающей волн $\mathrm{A} / \mathrm{R} ; E_{\text {пош }}$ - напряженность поля волны, прошедшей через образец, выделенная блоком В.

Результаты измерений частотных характеристик ослабления и отражения ЭМИ разработанными образцами 1082 и 1083 приведены на рис. 3.

Из-за наличия металлического слоя ослабление ЭМИ многослойными образцами составляет свыше 32 дБ в исследованных диапазонах частот.

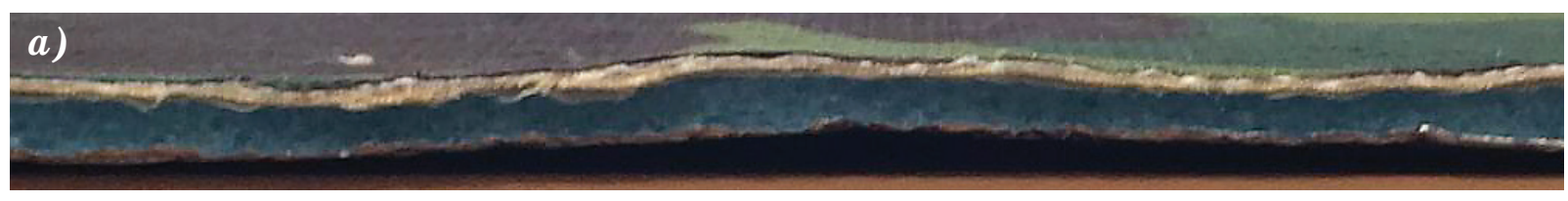

\section{б)}

Рuc. 1. Внешний вид поперечного сечения образцов многослойных экранирующих материалов: (а) 1082, 1083, 1084, 1086; (б) 1090-1

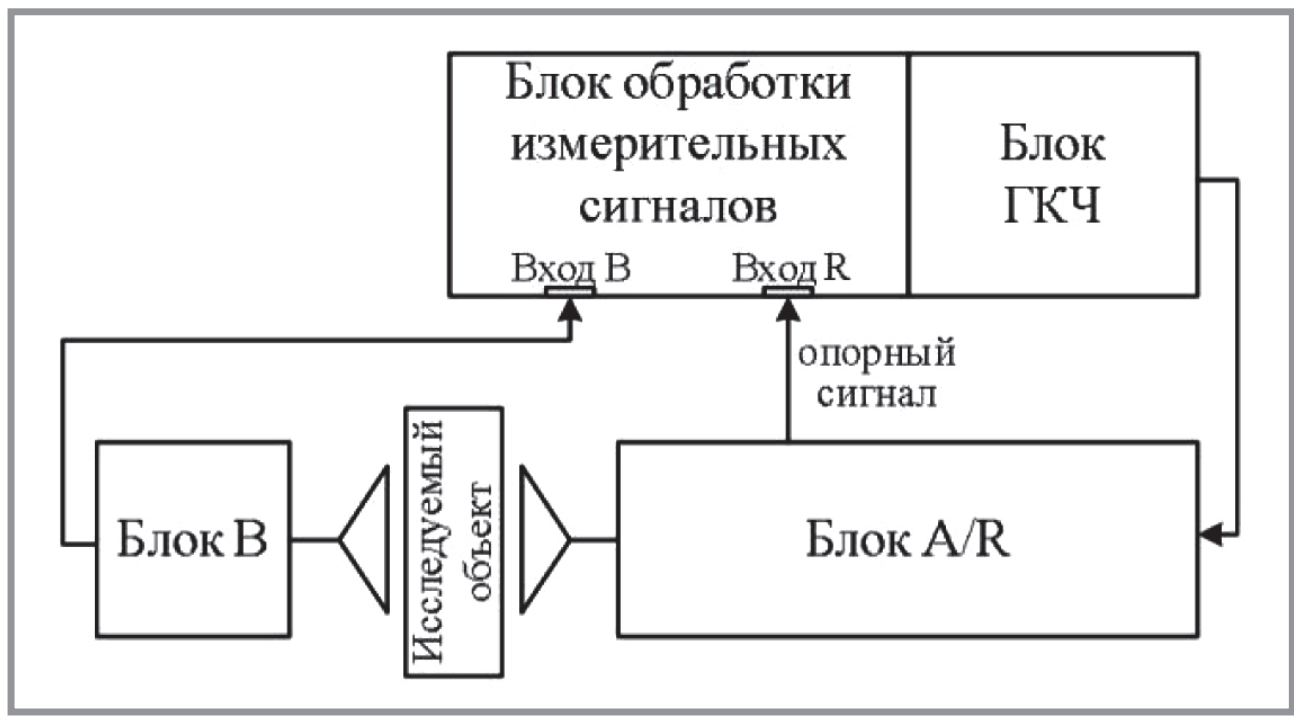

Рис. 2. Схема установки в режиме измерения ослабления ЭМИ 
a)

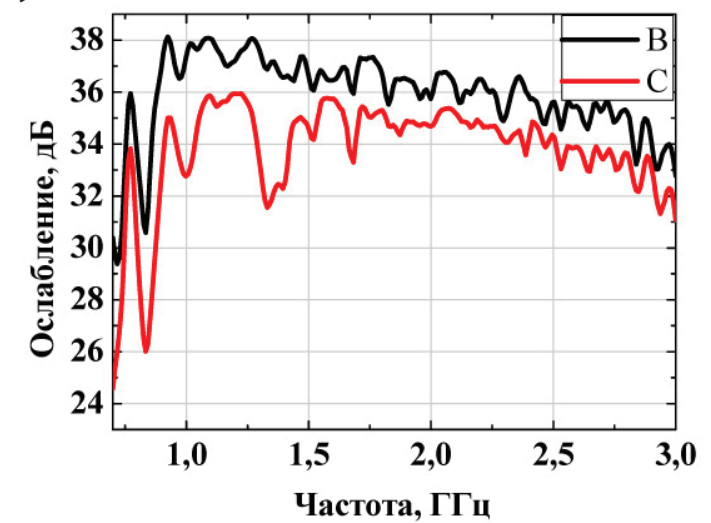

в)

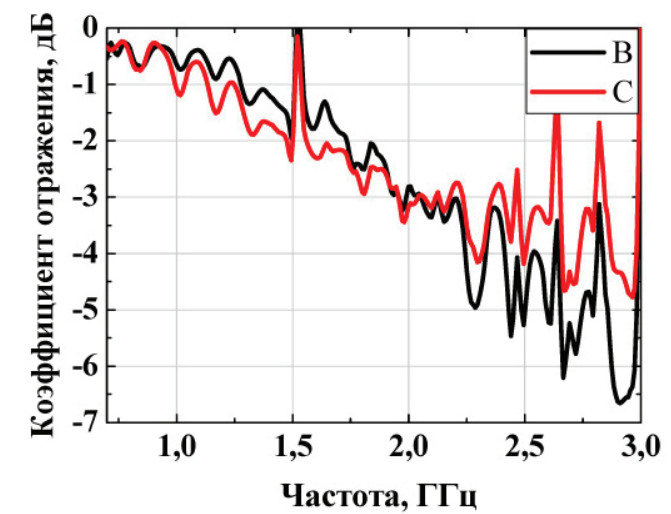

б)

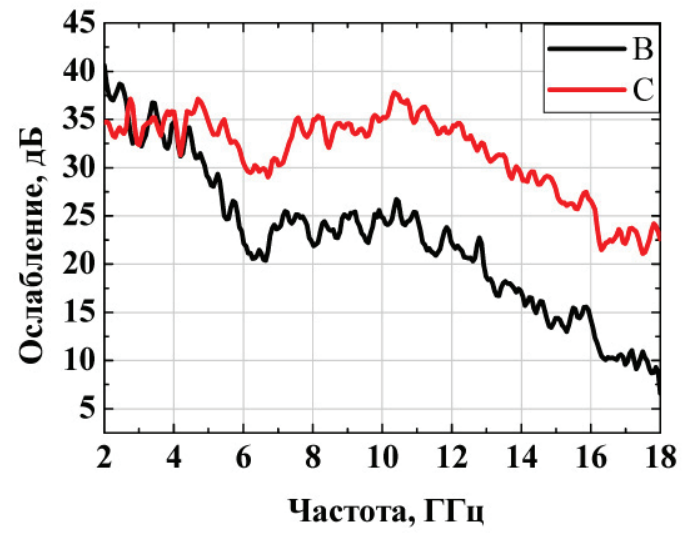

2)

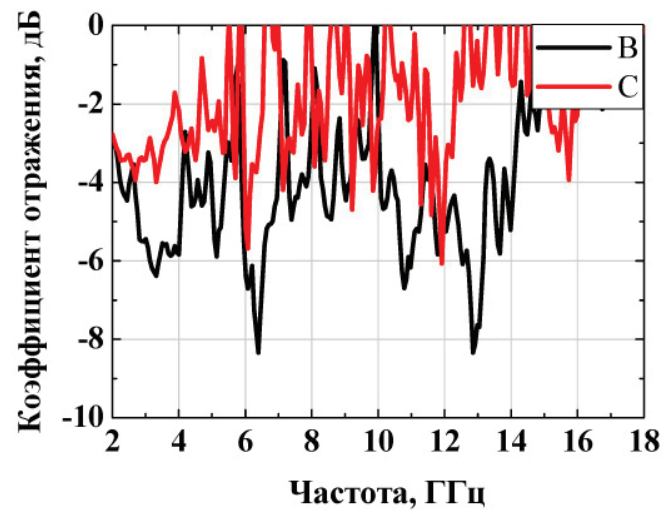

Рис. 3. Частотные зависимости ослабления (а, б) и коэффициентов отражения

(в, г) образцов многослойных конструкций для образцов без пропитки (В) и пропитанных водным раствором $\mathrm{CaCl}_{2}(\mathrm{C})$

Частотная характеристика коэффициента отражения ЭМИ неравномерна и изменяется от $0,5 . .-6,1$ дБ. В низкочастотном диапазоне коэффициент отражения достаточно высок $(-0,3 \ldots-1$ дБ), однако с увеличением частоты быстро убывает и в диапазоне частот $2,5 . .14$ ГГц ниже -4 дБ для образца с непропитанным полотном с ввязанным ферромагнитным микропроводом.

Уменьшение глубины проникновения поля в экранирующий материал с частотой выражается в снижении эффективности отражения мощности ЭМИ, а следовательно, и коэффициента отражения ЭМИ.

Пропитка полотна с магнитным материалом полярной жидкостью приводит к нарушению условий взаимодействия ЭМИ с материалом, 
и величина коэффициента отражения и частотный диапазон изменяются по сравнению с непропитанным материалом.

Помимо высокой эффективности экранирования готовые изделия должны обладать определенными эксплуатационными параметрами [13]. Применение экранирующих материалов для отделки помещений устанавливает определенные требования к ним по пожарной безопасности.

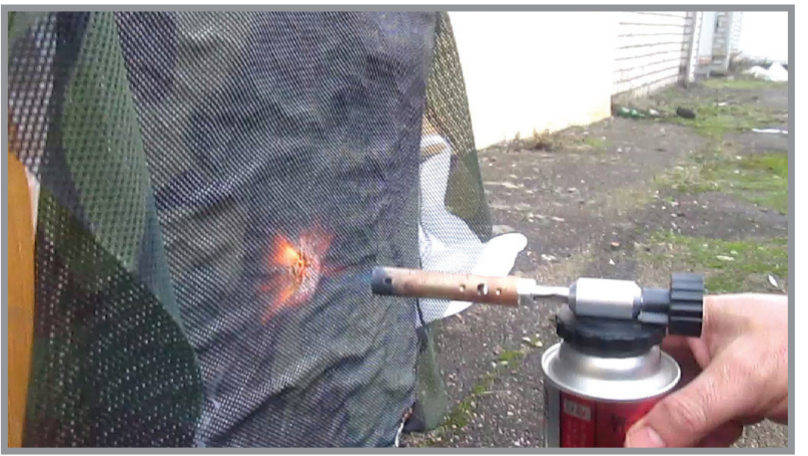

$1082(3 s)$

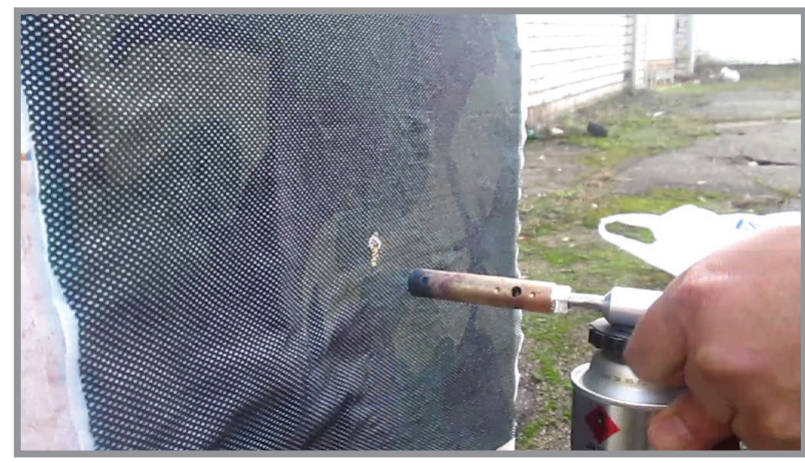

$1084(3 \mathrm{~s})$

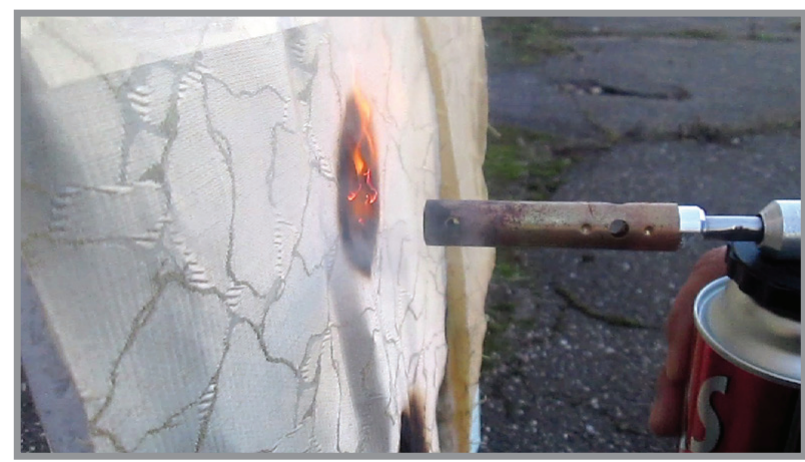

$1090(3 \mathrm{~s})$

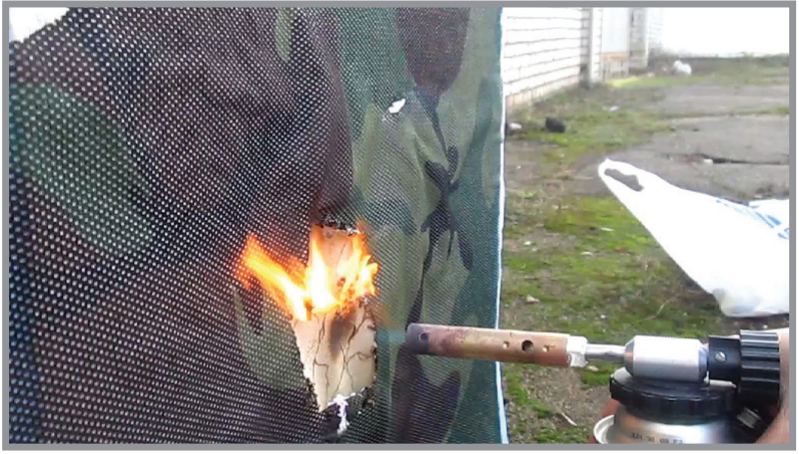

$1083(3 s)$

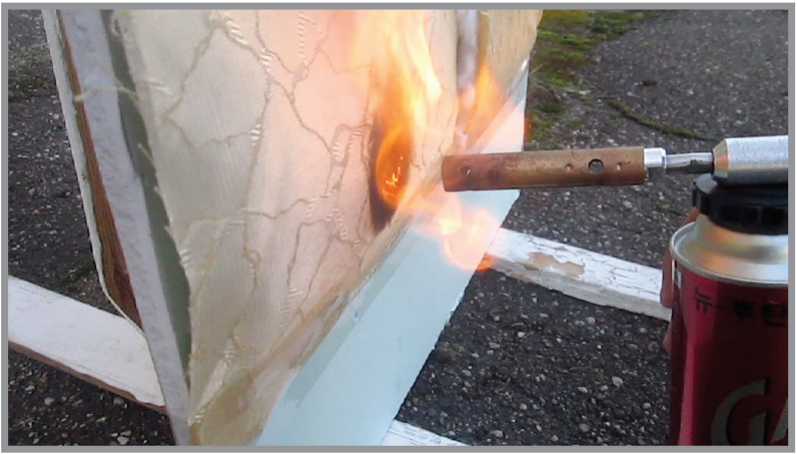

$1086(3 s)$

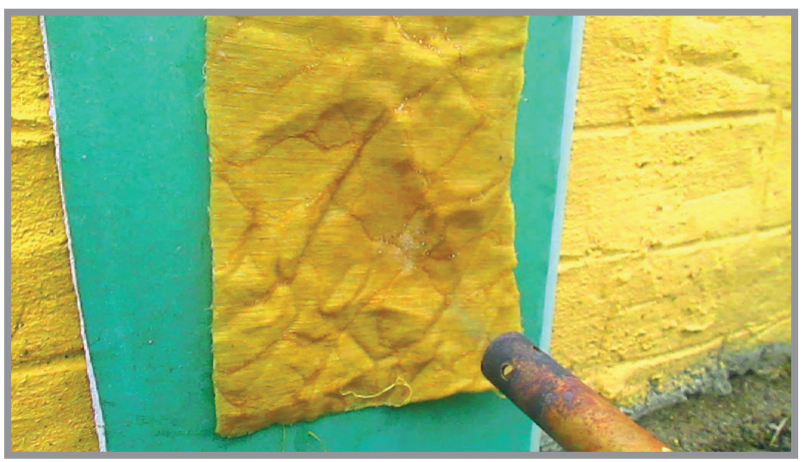

1091-1 (3 s)

Puc. 4. Фрагменты образцов многослойных конструкций при воздействии открытого пламени в течение 3 сек 
В соответствии с Нормами пожарной безопасности Республики Беларусь образцы имели размер 220x170 мм, испытания проводились в соответствии с [14]. Высоту пламени $\left(+1700^{\circ} \mathrm{C}\right)$ регулировали вентилем, и в вертикальном положении горелки она составляла $(40 \pm 2)$ мм.

В ходе исследования воздействия открытого пламени на образцы определялось время сквозного прогорания образцов. На рис. 4-7 приведены фотографии состояния поверхности образцов в течение эксперимента.

Как показали результаты исследований, время сквозного прогорания многослойных образцов из синтетических материалов без пропитки составило около 3 с. Образцы, в состав которых входит слой гипсокартона, разрушились до слоя гипсокартона, дальнейшего разрушения материала не произошло.

Воздействие открытого пламени в течение 30 с привело к испарению воды из слоя ПЭФ полотна с вплетенным ферромагнитным микропроводом образца 1084, после чего исходные слои материалов деструктировали.

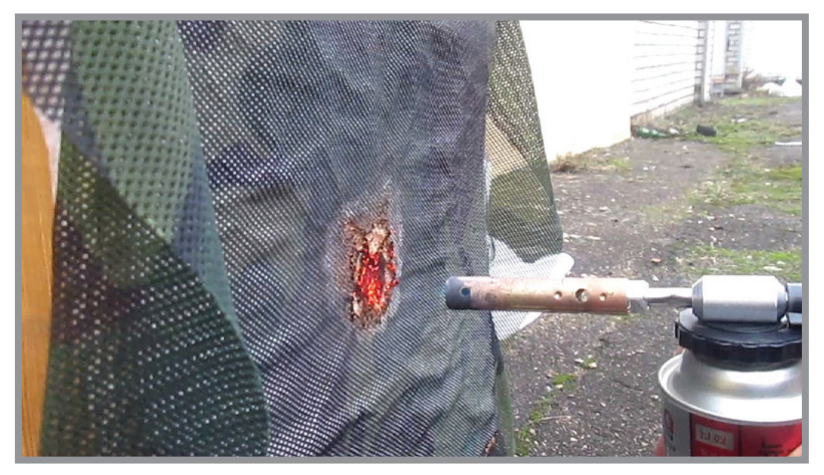

$1082(30 \mathrm{~s})$

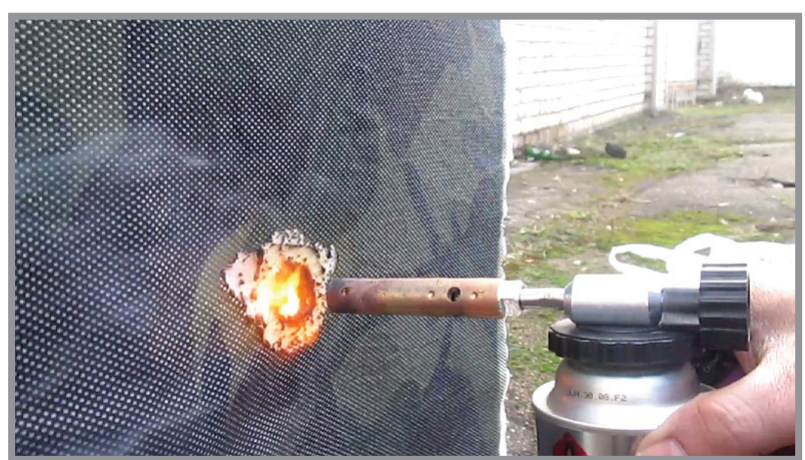

$1084(30 \mathrm{~s})$

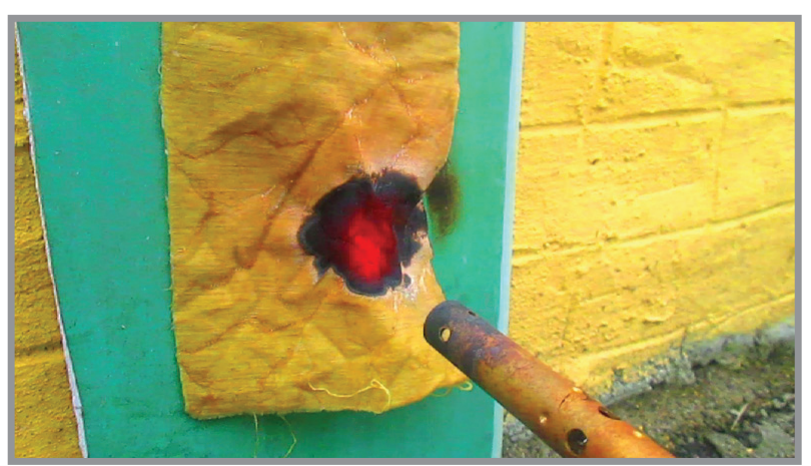

1091-1 (30 s)

Puc. 5. Фрагменты образцов многослойных конструкций при воздействии открытого пламени в течение 30 сек 


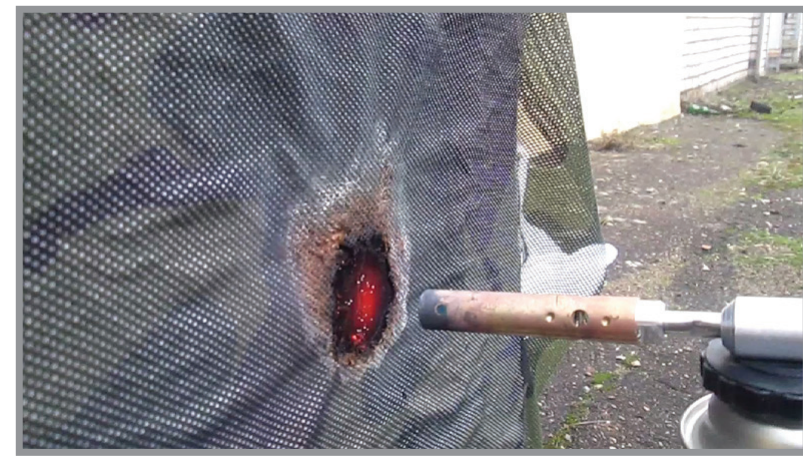

$1082(60 s)$

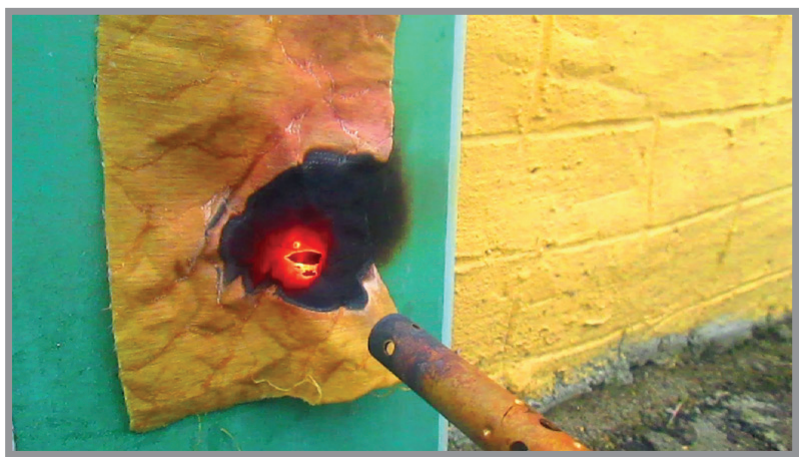

1091-1 (60 s)

Рuc. 6. Фрагменты образцов многослойных конструкций при воздействии открытого пламени в течение 60 сек

Более длительное воздействие открытого пламени привело к прогоранию образца 1091-1, состоящего из ПЭФ полотна с вплетенным ферромагнитным микропроводом, пропитанного водным раствором $\mathrm{CaCl}_{2}$, расположенным на слое гипсокартона толщиной 10 мм, через 60 с после начала воздействия.

Наибольшее время устойчивости к воздействию открытого пламени показал образец 1082, в котором для пропитки тканых полотен использовался водный раствор $\mathrm{CaCl}_{2}$. Это связано с тем, что на испарение молекул воды, связанных с молекулами гигроскопичной соли, поглотилось большее количество ИК-энергии, а оставшийся после испарения молекул воды $\mathrm{CaCl}_{2}$ под воздействием высокой температуры превратился в кокс - высокотемпературную керамику, выдерживающую воздействие высоких температур и экранирующую ИК-излучение.

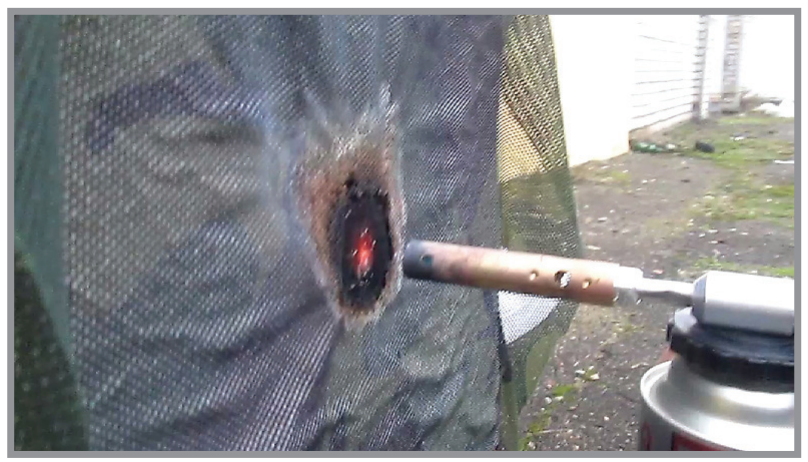

$1082(140 s)$

Рис. 7. Фрагменты образцов многослойных конструкций при воздействии открытого пламени в течение 140 сек 
В результате проведённой работы получены экранирующие характеристики (ослабление, коэффициент отражения ЭМИ) образцов многослойных экранирующих конструкций в виде отделочных панелей для интегрированных экранированных помещений. Показано, что использование композитов с магнитными и диэлектрическими потерями в многослойной структуре позволяет получить эффективность экранирования ЭМИ порядка $20 \ldots 35$ дБ в диапазоне частот $0,7 \ldots 17$ ГГц при коэффициенте отражения ЭМИ в пределах $-5 . . .-1$ дБ. В соответствии с Нормами пожарной безопасности РБ проведены испытания многослойных конструкций на время сквозного прогорания образцов. Установлено, что при воздействии открытого пламени $\left(+1700^{\circ} \mathrm{C}\right)$ на поверхность исследуемых образцов толщиной 0,3 мм, время прогорания многослойной экранирующей конструкции можно увеличить до 140 сек при использовании в составе композиционного материала гигроскопичных водных растворов.

\section{УВАЖАЕМЫЕ КОЛЛЕГИ!}

ПРИ ИСПОЛЬЗОВАНИИ МАТЕРИАЛА ДАННОЙ СТАТЬИ

ПРОСИМ ДЕЛАТЬ БИБЛИОГРАФИЧЕСКУЮ ССЫЛКУ НА НЕЁ:

Ахмед А.А., Насонова Н.В., Пулко Т.А., Лыньков Л.М. Отделочные панели для создания экранированных помещений на основе наноструктурированных композиционных материалов // Нанотехнологии в строительстве. - 2015. - Том 7, № 5. - C. 87-101. - DOI: dx.doi.org/10.15828/2075-8545-2015-7-5-87-101.

\section{DeAR COlleagues!}

THE REFERENCE TO THIS PAPER HAS THE FOLLOWING CITATION FORMAT:

Ahmed A.A., Nasonova N.V., Pulko T.A., Lynkov L.M. Finishing panels for electromagnetic shielded premises on the basis of nanostructured composite material. Nanotehnologii v stroitel'stve $=$ Nanotechnologies in Construction. 2015, Vol. 7, no. 5, pp. 87-101. DOI: dx.doi.org/10.15828/2075-8545-2015-7-5-87-101. (In Russian). 


\section{Библиографический список:}

1. Кечиев Л.Н., Степанов П.В. ЭМС и информационная безопасность в системах телекоммуникаций. - Москва: Издательский Дом «Технологии», 2005. - 320 с.

2. Акбашев Б.Б., Куприенко В.М. Концепция проектирования защиты объектов от внешних электромагнитных воздействий // Технологии электромагнитной совместимости. -2009 . - № 1. - С. 58-63.

3. Акбашев Б.Б. Экранированные помещения. - Москва: Изд. МИЭМ, 2008. - 175 с.

4. Уилльялс Т., Арлстронг К. ЭМС для систем и установок. - М.: Издательский Дом «Технологии», 2004. - 508 с.

5. Hemming L.H. Architectural Electromagnetic Shielding Handbook. A Design and Specification Guide. - IEEE Press, 1992. - 222 p.

6. Белоусова Е.С., Махмуд М.Ш., Льньков Л.М., Насонова Н.В. Радиоэкранирующие свойства бетонов на основе шунгитосодержащих наноматериалов // Нанотехнологии в строительстве. - 2013. - Том 5, № 2. - C. 56-67. - URL:http://nanobuild.ru/ru_RU (дата обращения: 12.04.2015).

7. Махмуд М.Ш., Пулко Т.А., Прудник А.М., Лыньков Л.М. Углеродсодержащие отделочные материалы для защиты помещений специального назначения / / Безопасность информационных технологий. - 2012. - № 1. - С. 192-194.

8. Махлуд М.Ш., Белоусова Е.С., Прудник А.М., Льньков Л.М. Влияние добавок бишофита на характеристики пирамидообразных экранов электромагнитного излучения для средств защиты информации и экологической безопасности // Доклады БГУИР. 2014. -№ 1 (79) - С. 89-92.

9. Казанцева Н.Е., Рывкина Н.Г., Члутин И.А. Перспективные материалы для поглотителей электромагнитных волн сверхвысокочастотного диапазона // Радиотехника и электроника. - 2003. - Т. 48, № 2. - С. 196-209.

10. Silva E., Rocha E.J., Lins P., Nóbrega S. Characterization of electromagnetic radiation absorber materials // IEEE MTT-S International Conference on Microwave and Optoelectronics. -2005 . - P. $326-329$.

11. Махмуд, М.Ш., Насонова Н.В., Криштопова Е.А., Борботько Т.В., Прудник А.М., Лыньков Л.М. Шунгитсодержащие композиционные экраны электромагнитного излучения. - Минск: Бестпринт, 2013. - 195 с.

12. Грищенкова В.А., Владимиров Д.Н., Фукина В.А., Хандогина Е.Н., Шаповалова Е.И. Ткань для защиты от электромагнитных излучений // Патент РФ 2411315. - 2011.

13. Белоусова E.C, Насонова Н.В., Лыньков Л.М.и др. Огнестойкое экранирующее покрытие на основе шунгитсодержащей краски / Н Нанотехнологии в строительстве. - 2013. Tom 5, № 4. - C. 97-109. - URL: http://nanobuild.ru/magazine/nb/Nanobuild_4_2013. pdf (дата обращения 05.05.2015).

14. ГОСТ 30402-96. Материалы строительные. Метод испытания на воспламеняемость. Москва: Изд. Минстрой России, 1996. - 33 с. 